\title{
Taxonomic Diversity of the D-Glucose Oxidation Pathway in the Enterobacteriaceae
}

\author{
ODILE M. M. BOUVET, ${ }^{*}$ PASCAL LENORMAND, AND PATRICK A. D. GRIMONT \\ Unité des Entérobactéries, Institut National de la Santé et de la Recherche Médicale Unité 199, \\ Institut Pasteur, F-75724 Paris Cedex 15, France
}

\begin{abstract}
Tests allowing the screening of large numbers of enterobacterial strains for the presence of the glucose oxidation pathway (glucose, gluconate, and 2-ketogluconate dehydrogenases) were devised or adapted. A total of 506 strains representing 111 taxa (named species or subspecies and unnamed genomic groups) were studied. The members of the genera Budvicia, Edwardsiella, Leminorella, Providencia, and Xenorhabdus and the species Citrobacter freundii, Erwinia carnegeana, Erwinia carotovora, Erwinia chrysanthemi, Erwinia nigrifluens, Erwinia salicis, Moellerella wisconsensis, Proteus penneri, Proteus vulgaris, Yersinia intermedia, Yersinia pestis, Yersinia pseudotuberculosis, and Yersinia ruckeri were negative in all tests. Five species, Erwinia cypripedii, Ewingella americana, Rahnella aquatilis, Serratia marcescens (at $20^{\circ} \mathrm{C}$ ), and Tatumella ptyseos produced 2,5-diketogluconate from glucose without a requirement for pyrroloquinoline quinone (PQQ). When PQQ was provided (required for glucose oxidation), Serratia grimesii and Serratia liquefaciens produced 2,5-diketogluconate from glucose at $20^{\circ} \mathrm{C}$. Escherichia blattae had gluconate- and 2-ketogluconate dehydrogenases without glucose dehydrogenase. The members of the genera Hafnia, Obesumbacterium, and Pragia had only gluconate dehydrogenase. Other species had glucose dehydrogenase (with or without a requirement for PQQ) with or without gluconate dehydrogenase. Classification and identification may take advantage of tests exploring the glucose oxidation pathway.
\end{abstract}

In bacteria which ferment glucose through the EmbdenMeyerhof pathway (e.g., members of the Enterobacteriaceae and Vibrionaceae), glucose is transported into the cells by the phosphoenolpyruvate sugar phosphotransferase system (PTS) $(4,17,20,21)$. In this process, glucose is concomitantly phosphorylated to glucose 6-phosphate. Strictly oxidative glucose utilizers (e.g., Pseudomonas spp.) often oxidize glucose to gluconate and 2-ketogluconate. Subsequently, these compounds are transported into the cells and are phosphorylated by adenosine triphosphatedependent kinases into 6-phosphogluconate and 2-keto-6phosphogluconate, which are then metabolized through the Entner-Doudoroff pathway (9) (Fig. 1).

Simple tests have been devised to differentiate oxidative from fermentative glucose utilization pathways. Hugh and Leifson (13) described a two-tube glucose medium; one of the tubes is kept anaerobic (closed tube), and the other is aerobic (open tube). Acid production in the closed tube indicates fermentative metabolism, and acid production in only the open tube indicates oxidative metabolism. Fermentative bacteria, such as members of the Enterobacteriaceae, commonly produce acid in both tubes, and this does not imply an ability to oxidize glucose (in addition to the known ability to ferment glucose).

Since iodoacetate inhibits at some point glucose fermentation, Lysenko (15) proposed a glucose broth, supplemented with $1 \mathrm{mM}$ iodoacetate and a $\mathrm{pH}$ indicator, to discriminate between oxidative bacteria (e.g., Pseudomonas spp.) and fermentative bacteria (e.g., members of the Enterobacteriaceae, Vibrionaceae, and Aeromonadaceae). Although it was later shown that some members of the Enterobacteriaceae produce acid from glucose in the presence of iodoacetate (10), this test has seldom been used in taxonomy.

Gluconate is a nonreducing compound, whereas 2-keto-

\footnotetext{
* Corresponding author.
}

gluconate (an oxidation product of gluconate) is a reducing compound. Haynes (11) devised a simple test consisting of the detection of a reducing compound produced by bacteria grown in a gluconate medium. Again, the test was aimed at differentiating members of the Pseudomonadaceae from members of the Enterobacteriaceae. Later, it became obvious that several species of the Enterobacteriaceae can produce reducing compounds from gluconate $(2,10)$, and workers have found proof that glucose can be oxidized to gluconate and to 2-ketogluconate $(5,18,19,23)$.

It was recently found that Escherichia coli can oxidize glucose if it is provided with a cofactor, pyrroloquinoline quinone (PQQ) (12). Escherichia coli glucose dehydrogenase was found located on the outer surface of the cytoplasmic membrane (16), and the role of PQQ and the respiratory chain in microbial oxidations has been discussed (7).

A few bacterial species, including Acetobacter melanogenum, Gluconobacter oxydans, and Janthinobacterium lividum, have been shown to accumulate 2,5-diketogluconate as an end product of glucose oxidation $(3,8,14)$. It was recently found that Erwinia cypripedii is also capable of producing 2,5-diketogluconate (5).

The purposes of this study were to propose tests for screening for bacterial glucose, gluconate, and 2-ketogluconate dehydrogenases and to study the distribution of the glucose oxidation pathway among enterobacterial species.

\section{MATERIALS AND METHODS}

Bacterial strains. A total of 506 strains representing 111 taxa (named species or subspecies and genomic species) of the Enterobacteriaceae were studied. Type strains and strains used as references in deoxyribonucleic acid (DNA) relatedness studies were included.

Reagents. $\mathrm{D}-\left[\mathrm{U}-{ }^{14} \mathrm{C}\right] \mathrm{glucose}(275 \mathrm{mCi} / \mathrm{mmol})$ was obtained from Amersham International, Amersham, England, and was used at an activity of $2 \mu \mathrm{Ci} / \mu \mathrm{mol}$. Sodium D-gluconate, hemicalcium 2-keto-D-gluconate, sodium iodoacetate, and 
Extracellular medium

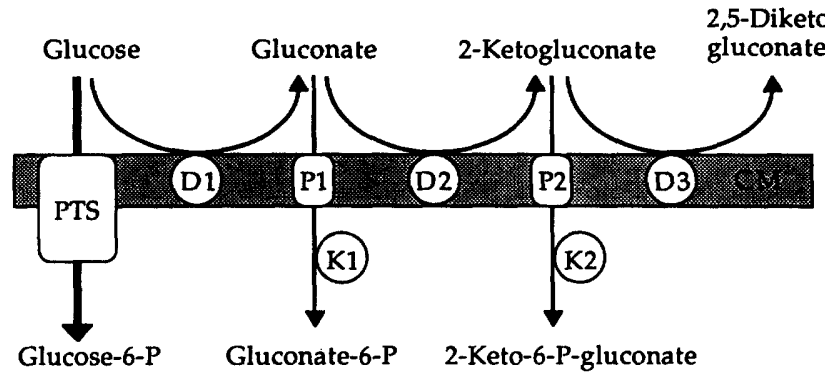

Cytoplasm

FIG. 1. Schematic representation of glucose entry routes in the Enterobacteriaceae. CM, Cytoplasmic membrane; D1, glucose dehydrogenase; D2, gluconate dehydrogenase; D3, 2-ketogluconate dehydrogenase; $\mathrm{P} 1$, active transport for gluconate; $\mathrm{P} 2$, transport of 2-ketogluconate (not well known); K1, gluconate kinase; K2, 2 ketogluconate kinase. P, phosphate (in chemical names). The PTS includes membrane-bound and soluble proteins. Iodoacetate inhibits the PTS and not the dehydrogenases.

sodium dodecyl sulfate were obtained from Sigma Chemical Co., St. Louis, Mo. D-Glucose, acetic acid, sodium acetate, magnesium sulfate, Triton X-100, and 85\% o-phosphoric acid were purchased from Merck-Schuchardt, Darmstadt, Federal Republic of Germany. $\mathrm{HCl}$, potassium ferricyanide, and ferric sulfate were obtained from Prolabo, Paris, France. 2,7,9 - Tricarboxy - $1 \mathrm{H}$ - pyrrolo - [2,3f] - quinoline - 4,5 - dione (PQQ) was obtained from Fluka AG, Buch, Switzerland. This chemical is also available from Sigma under the name 4,5-dihydro-4,5-dioxo-1H-pyrrolo-[2,3f]-quinoline-2,7,9-tricarboxylic acid (common name, pyrroloquinoline quinone).

Aerobic acid production from glucose in the presence of iodoacetate (glucose oxidation test). The Lysenko test (15) was extensively modified to give results in accord with the results of tests in which isotopically labeled D-glucose was used. The modified test is intended for routine screening of glucose oxidation by members of the Enterobacteriaceae. A 1-liter portion of glucose oxidation medium was composed of basal medium containing $8 \mathrm{~g}$ of nutrient broth (Difco Laboratories, Detroit, Mich.), $0.02 \mathrm{~g}$ of bromcresol purple, and $0.62 \mathrm{~g}$ of $\mathrm{MgSO}_{4} \cdot 7 \mathrm{H}_{2} \mathrm{O}(2.5 \mathrm{mM})$. To $9.2 \mathrm{ml}$ of autoclaved $\left(121^{\circ} \mathrm{C}, 15 \mathrm{~min}\right)$ basal medium we added $0.4 \mathrm{ml}$ of a filter sterilized $1 \mathrm{M}$ D-glucose solution (final concentration, 40 $\mathrm{mM}$ ). This medium was supplemented with $0.4 \mathrm{ml}$ of a fresh, sterile $25 \mathrm{mM}$ iodoacetate solution (final concentration, 1 $\mathrm{mM}$ ). In some experiments, the medium was also supplemented with 10 or $100 \mu \mathrm{M}$ PQQ. The glucose oxidation medium was distributed $(0.5-\mathrm{ml}$ portions) into glass tubes (11 by $75 \mathrm{~mm}$ ) which were plugged with sterile cotton wool. Bacteria grown overnight at 20 or $30^{\circ} \mathrm{C}$ on tryptocasein soy agar (Diagnostics Pasteur, Marnes-la Coquette, France) supplemented with $0.2 \%$ (wt/vol) D-glucose were collected with a platinum loop, suspended in a sterile $2.5 \mathrm{mM} \mathrm{MgSO}_{4}$ solution, and adjusted to an absorbance (at $600 \mathrm{~nm}$ ) of about 4. Glucose oxidation medium was then inoculated with $50 \mu \mathrm{l}$ of bacterial suspension and vigorously shaken at 270 strokes per minute (type AVG shaker; Jean Robin, Angers, France) overnight at 20 or $30^{\circ} \mathrm{C}$. The test was positive when a yellow color developed (acid production). Otherwise, the medium remained purple. The control strains which we used were Escherichia coli K-12 (negative) and Serratia marcescens $504^{\mathrm{T}}\left(\mathrm{T}=\right.$ type strain) (positive) at both 20 and $30^{\circ} \mathrm{C}$.

Oxidation of $\left[{ }^{14} \mathrm{C}\right]$ glucose by nonproliferating cells. The test for oxidation of $\left[{ }^{14} \mathrm{C}\right]$ glucose by nonproliferating cells was used as a reference test for glucose oxidation in the presence and in the absence of 10 or $100 \mu \mathrm{M}$ PQQ. Oxidation of 15 $\mathrm{mM}\left[{ }^{14} \mathrm{C}\right]$ glucose by shaken bacterial suspensions was studied as described previously (5). Samples $(50 \mu l)$ were withdrawn at 0,30 , and 60 min and immediately mixed with 2.5 $\mathrm{mM}$ ethylenediaminetetraacetic acid to stop the oxidation reaction. After centrifugation at $10,000 \times g$ for $10 \mathrm{~min}, 10-\mu \mathrm{l}$ portions of supernatants were spotted onto diethylaminoethyl cellulose strips (type DE81; Whatman, Maidstone, England) and chromatographed (5). The strips were then cut into four pieces, and the radioactivity of each piece was counted by liquid scintillation (5). This method allowed us to separate oxidation products (gluconate, 2-ketogluconate, or 2,5-diketogluconate), which migrated half way, from phosphorylated products, which did not migrate, and from unmodified glucose, which migrated to the front (5).

Oxidation products of glucose, gluconate, or 2-ketogluconate in cultures. The experiment to determine the oxidation products of glucose, gluconate, or 2-ketogluconate in cultures has been described previously (5). Briefly, bacteria were grown in Erlenmeyer flasks containing nutrient broth and either $40 \mathrm{mM}\left[{ }^{14} \mathrm{C}\right]$ glucose, $40 \mathrm{mM}$ gluconate, or $40 \mathrm{mM}$ 2-ketogluconate with shaking at $30^{\circ} \mathrm{C}$. Samples were withdrawn at 6 and $24 \mathrm{~h}$, and the oxidation products were assayed by diethylaminoethyl cellulose chromatography and scintillation counting (for $\left[{ }^{14} \mathrm{C}\right]$ glucose-grown bacteria) or identified after cellulose thin-layer chromatography by spraying the plaques with $o$-phenylenediamine hydrochloride, using the method of Gosselé et al. (8). The $o$-phenylenediamine hydrochloride reagent does not stain gluconate spots. The staining reactions of glucose, 2-ketogluconate, 5-ketogluconate, and 2,5-diketogluconate have been described previously (8).

Gluconate dehydrogenase test. The methods of Ameyama (1) and Shinagawa et al. (22) were modified for the detection of gluconate dehydrogenase in cell suspensions. Bacteria were grown overnight at 20 or $30^{\circ} \mathrm{C}$ on tryptocasein soy agar supplemented with $0.2 \%$ D-gluconate. The bacterial growth was then collected with a platinum loop and suspended in sterile distilled water to an absorbance (at $600 \mathrm{~nm}$ ) of about 4. The reaction medium contained $0.2 \mathrm{M}$ acetate buffer $(\mathrm{pH}$ 5), $1 \%$ (wt/vol) Triton X-100, $2.5 \mathrm{mM} \mathrm{MgSO}_{4}, 75 \mathrm{mM}$ gluconate, and (added immediately before use) $1 \mathrm{mM}$ iodoacetate. A control medium contained the same ingredients except gluconate. The reaction medium and the control medium were dispensed (100- $\mu$ l portions) into 96-well microtiter plates (Dynatech AG, Denkendorf, Federal Republic of Germany). Bacterial suspensions $(10 \mu \mathrm{l})$ were added to the reaction and control media, and the microtiter plates were incubated at 20 or $30^{\circ} \mathrm{C}$ for $20 \mathrm{~min}$. Then, $10-\mu l$ portions of a $0.1 \mathrm{M}$ potassium ferricyanide solution (kept in the dark at room temperature for no longer than 1 week) were added to the wells, and the plates were gently shaken and incubated at 20 or $30^{\circ} \mathrm{C}$ for $40 \mathrm{~min}$. Then $50-\mu \mathrm{l}$ portions of a reagent $\left(\mathrm{Fe}_{2}\left(\mathrm{SO}_{4}\right)_{3}, 0.6 \mathrm{~g}\right.$; sodium dodecyl sulfate, $0.36 \mathrm{~g} ; 85 \%$ phosphoric acid, $11.4 \mathrm{ml}$; distilled water to $100 \mathrm{ml}$ ) were added to the wells. The plates were examined for the development of a green to blue color (due to Prussian blue) within $15 \mathrm{~min}$ at room temperature. The color in the uninoculated control medium remained yellow. The control strains which we used were Escherichia coli $\mathrm{K}-12$ (negative) and Serratia marcescens $504^{\mathrm{T}}$ (positive).

2-Ketogluconate dehydrogenase test. The 2-ketogluconate dehydrogenase test was the same as the test for gluconate dehydrogenase, except that the control and reaction media 
were adjusted to $\mathrm{pH} 4.0$ and 2-ketogluconate was used in place of gluconate in the reaction medium. 2-Ketogluconate solutions should be fresh or kept frozen before use. The control strains which we used were Escherichia coli $\mathrm{K}-12$ (negative) and Erwinia cypripedii ICPB EC155 (positive).

\section{RESULTS AND DISCUSSION}

Oxidation of $\left[{ }^{14} \mathrm{C}\right]$ glucose in culture or by nonproliferating cells. A total of 189 strains representing all of the species listed in Table 1 were studied for oxidation of $\left[{ }^{14} \mathrm{C}\right]$ glucose in cultures in the absence of added PQQ; 69 strains representing 27 genomic species accumulated nonphosphorylated radioactive oxidation products of glucose (gluconate and gluconate oxidation products) in the culture supernatant. From $40 \mathrm{mM}$ D-glucose, these strains produced 8 to 34 and 19 to $34 \mathrm{mM}$ gluconate in 6 and $18 \mathrm{~h}$, respectively. Strains of Yersinia frederiksenii, Yersinia kristensenii, and Yersinia enterocolitica were the slowest producers, as determined previously (5).

A total of 120 strains representing 74 named or genomic species failed to produce radioactive oxidation products (less than $1 \%$ of input radioactivity) from $\left[{ }^{14} \mathrm{C}\right]$ glucose.

Validity of the test for acid production from glucose under strongly aerobic conditions and in the presence of iodoacetate (glucose oxidation test). Preliminary experiments in which we used the Lysenko test (15) showed many discrepancies with the radioactive tests. A new test was then designed in light of recently acquired knowledge (5). The constraints were as follows: (i) the medium should contain growth factors needed by auxotrophic species (e.g., Edwardsiella spp.); (ii) the buffering capacity should be low enough to allow a suicide accumulation of gluconate, thus avoiding metabolism of acid products during incubation; (iii) the $\mathrm{pH}$ indicator should detect even low production of gluconate (e.g., by Yersinia frederiksenii); (iv) magnesium ion should be present since the glucose dehydrogenase of some bacteria (e.g., Klebsiella pneumoniae) requires this ion (19); (v) since bacterial cells (and not cell extracts) were used, the phosphoenolpyruvate-dependent PTS should be inhibited; (vi) prior induction by growth on a glucose medium and strong aeration has been shown to improve oxidation rates $(5,18)$; and (vii) the correlation between the results of the new test and the results of radioactive tests should be as close as possible. Recent work has demonstrated the complete inhibition of the PTS by iodoacetate (4) without inhibition of glucose dehydrogenase (5). In glucose oxidation medium, glucose-oxidizing enterobacterial strains were found to lower the $\mathrm{pH}$ in the medium from 7.0 to less than 3.5. The test lacked sensitivity when nutrient broth was replaced by Difco Proteose Peptone no. 3 or by the peptone water currently in use at the Institut Pasteur for fermentation tests. The chosen $\mathrm{pH}$ indicator (bromcresol purple) is purplish blue above $\mathrm{pH} 6.8$ and yellow below $\mathrm{pH} 5.2$, a range which was found to be convenient. All 69 strains which oxidized glucose in radioactive tests produced acid in the glucose oxidation medium, and the 120 strains which failed to oxidize glucose in radioactive tests also failed to produce acid in the glucose oxidation medium. Of the 386 strains studied by the glucose oxidation test with $10 \mu \mathrm{m}$ PQQ, 30 were checked for oxidation of $\left[{ }^{14} \mathrm{C}\right]$ glucose by resting cells, and no discrepancy was observed. The results were not modified by adding $100 \mu \mathrm{M}$ PQQ instead of $10 \mu \mathrm{M}$ PQQ or by doing the test at $20^{\circ} \mathrm{C}$ instead of $30^{\circ} \mathrm{C}$.

The results of the glucose oxidation test for 402 strains are shown in Table 1 . The fact that all of the strains of a species showed only one type of reaction strengthens the validity of the test. Different results occurred in a few species (Cedecea lapagei, Serratia plymuthica, Yersinia enterocolitica, and Yersinia frederiksenii). These results were checked and confirmed by radioactive tests. In glucose oxidation tests with PQQ, different results occurred in Salmonella enterica subsp. enterica and Shigella spp. These results were confirmed by radioactive tests.

The glucose oxidation test described here seems more restrictive than the Lysenko test (15). The Lysenko test was positive for members of the genus Serratia, including Serratia liquefaciens, Serratia proteamaculans, and Serratia grimesii (formerly called Serratia liquefaciens C1ab, C1c, and C1d, respectively) (10), whereas the glucose oxidation test (in the absence of PQQ) was negative for these three species.

Validity of the tests for gluconate dehydrogenase and 2ketogluconate dehydrogenase. The gluconate and 2-ketogluconate dehydrogenase tests were adapted from the tests of Ameyama (1) for use with whole bacterial cells. Clear results (for both dehydrogenase tests) were obtained by using bacterial cells grown on a medium containing gluconate. These tests had to be validated by parallel determination of glucose, gluconate, or 2-ketogluconate oxidation end products.

All 61 strains which produced chromatographically identified 2-ketogluconate in cultures with D-glucose or D-gluconate gave positive tests for gluconate dehydrogenase. All 92 strains which were unable to produce 2-ketogluconate (screened by chromatography) were negative in the gluconate dehydrogenase test. Tests done at $20^{\circ} \mathrm{C}$ gave the same results as tests done at $30^{\circ} \mathrm{C}$.

This gluconate dehydrogenase test might not give the same results as the Haynes test (11). The Haynes test was positive for a phenon composed of Enterobacter cloacae, Enterobacter nimipressuralis, and Enterobacter sakazakii (10), whereas gluconate dehydrogenase was not produced by these species. In the data matrix of Bascomb et al. (2), results of the Haynes test (called the gluconate reduction test) were reported for 31 enterobacterial species. The results of our gluconate dehydrogenase test agree with the results of Bascomb et al. (2) except for Enterobacter cloacae and Proteus mirabilis.

All 14 strains which produced chromatographically identified 2,5-diketogluconate in cultures with D-glucose, Dgluconate, or 2-ketogluconate gave positive tests for 2ketogluconate dehydrogenase. The 139 strains which failed to produce detectable amounts of 2,5-diketogluconate were negative in the 2-ketogluconate test. The results varied with the incubation temperature. Serratia liquefaciens, Serratia grimesii, and Serratia marcescens produced 2,5-diketogluconate at $20^{\circ} \mathrm{C}$ but did not produce this compound or produced only traces of it at $30^{\circ} \mathrm{C}$. This fact was overlooked in a recent study because all of the tests were done at $30^{\circ} \mathrm{C}$ (5). It should be noted that for both dehydrogenase tests, all of the species tested were homogeneous in their reactions.

Taxonomic interest of tests exploring the glucose oxidation pathway of members of the Enterobacteriaceae. The results of the glucose oxidation test with or without PQQ, the gluconate dehydrogenase test, and the 2-ketogluconate dehydrogenase test given by 111 taxa (named species or subspecies and unnamed genomic species) in the Enterobacteriaceae are shown in Table 1. The members of the genera Budvicia, Edwardsiella (three species), Leminorella (two species and an unnamed genomic group), Providencia (five species), and Xenorhabdus (two species), the species Citrobacter freundii, Erwinia carnegeana, Erwinia carotovora, Erwinia chrysan- 
TABLE 1. Oxidation of glucose, gluconate, and 2-ketogluconate by members of the Enterobacteriaceae

\begin{tabular}{|c|c|c|c|c|}
\hline \multirow{3}{*}{ Taxon } & \multicolumn{4}{|c|}{ Oxidation of: } \\
\hline & \multicolumn{2}{|c|}{ Glucose to gluconate ${ }^{a}$} & \multirow{2}{*}{$\begin{array}{l}\text { Gluconate } \\
\text { to } 2-\mathrm{KG}^{b}\end{array}$} & \multirow{2}{*}{$\begin{array}{l}2-\mathrm{KG} \text { to } \\
2,5-\mathrm{KG}^{c}\end{array}$} \\
\hline & $-\mathrm{PQQ}$ & $+\mathrm{PQQ}$ & & \\
\hline Budvicia aquatica & $-(0 / 3)^{d}$ & $-(0 / 2)$ & $-(0 / 3)$ & $-(0 / 2)$ \\
\hline Buttiauxella agrestis & $-(0 / 2)$ & $+(2 / 2)$ & $-(2 / 2)$ & $-(0 / 2)$ \\
\hline Cedecea davisae & $-(0 / 5)$ & $+(5 / 5)$ & $-(0 / 5)$ & $-(0 / 5)$ \\
\hline Cedecea lapagei & d (4/5) & $+(5 / 5)$ & $-(0 / 5)$ & $-(0 / 5)$ \\
\hline Citrobacter amalonaticus & $-(0 / 5)$ & $+(5 / 5)$ & $-(0 / 5)$ & $-(0 / 4)$ \\
\hline Citrobacter diversus & $-(0 / 5)$ & $+(5 / 5)$ & $-(0 / 5)$ & $-(0 / 3)$ \\
\hline Citrobacter freundii & $-(0 / 3)$ & $-(0 / 3)$ & $-(0 / 3)$ & $-(0 / 3)$ \\
\hline Edwardsiella hoshinae & $-(0 / 5)$ & $-(0 / 5)$ & $-(0 / 5)$ & $-(0 / 5)$ \\
\hline Edwardsiella ictaluri & $-(0 / 3)$ & $-(0 / 3)$ & $-(0 / 3)$ & $-(0 / 3)$ \\
\hline Edwardsiella tarda & $-(0 / 5)$ & $-(0 / 3)$ & $-(0 / 5)$ & $-(0 / 5)$ \\
\hline Enterobacter aerogenes & $+(5 / 5)$ & ND & $+(5 / 5)$ & $-(0 / 3)$ \\
\hline \multicolumn{5}{|l|}{ Enterobacter agglomerans ${ }^{e}$} \\
\hline Enterobacter agglomerans sensu stricto & $+(5 / 5)$ & ND & $+(5 / 5)$ & $-(0 / 5)$ \\
\hline Group II strain $3123-70$ & + & ND & + & - \\
\hline Group III strain $1429-71$ & + & ND & + & - \\
\hline Group IV strain $1741-71$ & + & ND & + & - \\
\hline Group V strain 3482-71 & + & ND & + & - \\
\hline Group VI strain 6070-71 & + & ND & + & - \\
\hline Group VII strain $6003-71$ & - & + & - & - \\
\hline Group VIII strain 5422-69 & $\sim$ & - & - & - \\
\hline Group IX strain 4388-71 & + & ND & - & - \\
\hline Group $X$ strain $1600-71$ & - & + & - & - \\
\hline Group XI strain 5373-71 & - & + & - & - \\
\hline Group XII strain $219-71$ & - & + & - & - \\
\hline Enterobacter asburiae & $-(0 / 7)$ & $+(7 / 7)$ & $-(0 / 7)$ & $-(0 / 7)$ \\
\hline Enterobacter cloacae group $1^{f}$ & $-(0 / 3)$ & $+(2 / 2)$ & $-(0 / 3)$ & $-(0 / 2)$ \\
\hline Enterobacter cloacae group 2 & $-(0 / 5)$ & $+(5 / 5)$ & $-(0 / 5)$ & $-(0 / 5)$ \\
\hline Enterabacter cloacae group 3 & $+(6 / 6)$ & ND & $-(0 / 6)$ & $-(0 / 6)$ \\
\hline Enterobacter cloacae group 6 & $-(0 / 2)$ & $+(2 / 2)$ & $-(0 / 2)$ & $-(0 / 2)$ \\
\hline Enterobacter gergoviae & $+(4 / 4)$ & ND & $+(4 / 4)$ & $-(0 / 4)$ \\
\hline Enterobacter intermedium & $-(0 / 5)$ & $+(5 / 5)$ & $-(0 / 5)$ & $-(0 / 3)$ \\
\hline Enterobacter nimipressuralis & $-(0 / 4)$ & $+(4 / 4)$ & $-(0 / 4)$ & $-(0 / 3)$ \\
\hline Enterobacter sakazakii & $+(5 / 5)$ & ND & $-(0 / 5)$ & $-(0 / 5)$ \\
\hline Enterobacter taylorae & $-(0 / 6)$ & $+(6 / 6)$ & $-(0 / 6)$ & $-(0 / 6)$ \\
\hline Erwinia amylovora & $-(0 / 3)$ & $+(3 / 3)$ & $-(0 / 3)$ & $-(0 / 3)$ \\
\hline Erwinia cancerogena & $-(0 / 2)$ & $+(2 / 2)$ & $-(0 / 2)$ & $-(0 / 2)$ \\
\hline Erwinia carnegeana EC 186 & - & - & - & - \\
\hline Erwinia carotovora & $-(0 / 6)$ & $-(0 / 3)$ & $-(0 / 6)$ & $-(0 / 3)$ \\
\hline Erwinia chrysanthemi & $-(0 / 8)$ & $-(0 / 3)$ & $-(0 / 8)$ & $-(0 / 3)$ \\
\hline Erwinia cypripedii ICPB EC155 & + & ND & + & + \\
\hline Erwinia herbicola & $+(2 / 2)$ & ND & $+(2 / 2)$ & $-(0 / 2)$ \\
\hline Erwinia mallotivora 2851 & - & + & - & - \\
\hline Erwinia nigrifluens EN 104 & - & - & - & - \\
\hline Erwinia quercina 102 & - & + & - & - \\
\hline Erwinia rhapontici & $+(3 / 3)$ & ND & $+(3 / 3)$ & $-(0 / 3)$ \\
\hline Erwinia rubrifaciens & $-(0 / 2)$ & $-(0 / 2)$ & $-(0 / 2)$ & $-(0 / 2)$ \\
\hline Erwinia salicis & $-(0 / 2)$ & $-(0 / 2)$ & $-(0 / 2)$ & $-(0 / 2)$ \\
\hline Escherichia blattae & $-(0 / 2)$ & $-(0 / 2)$ & $+(2 / 2)$ & $+(2 / 2)$ \\
\hline \multicolumn{5}{|l|}{ Escherichia coli genomic group } \\
\hline Prototrophs ${ }^{g}$ & $-(0 / 5)$ & $+(5 / 5)$ & $-(0 / 5)$ & $-(0 / 5)$ \\
\hline Shigella dysenteriae & $-(0 / 15)$ & $\mathrm{d}(6 / 15)^{h}$ & $-(0 / 15)$ & $-(0 / 15)$ \\
\hline Shigella fiexneri & $-(0 / 10)$ & $+(10 / 10)$ & $-(0 / 10)$ & $-(0 / 10)$ \\
\hline Shigella boydii & $-(0 / 13)$ & $\mathrm{d}(7 / 13)^{i}$ & $-(0 / 13)$ & $-(0 / 13)$ \\
\hline Shigella sonnei & $-(0 / 5)$ & $+(5 / 5)$ & $-(0 / 5)$ & $-(0 / 5)$ \\
\hline Escherichia fergusonii & $-(0 / 4)$ & $+(4 / 4)$ & $-(0 / 4)$ & $-(0 / 4)$ \\
\hline Escherichia hermanii & $-(0 / 5)$ & $+(5 / 5)$ & $-(0 / 5)$ & $-(0 / 5)$ \\
\hline Escherichia vulneris & $-(0 / 4)$ & $+(4 / 4)$ & $-(0 / 4)$ & $-(0 / 3)$ \\
\hline Ewingella americana & $+(5 / 5)$ & ND & $+(5 / 5)$ & $+(5 / 5)$ \\
\hline Hafnia alvei & $-(0 / 13)$ & $-(0 / 13)$ & $+(13 / 13)$ & $-(0 / 13)$ \\
\hline Klebsiella oxytoca & $-(0 / 4)$ & $+(4 / 4)$ & $-(0 / 4)$ & $-(0 / 4)$ \\
\hline Klebsiella planticola & $-(0 / 4)$ & $+(4 / 4)$ & $+(4 / 4)$ & $-(0 / 4)$ \\
\hline Klebsiella pneumoniae subsp. pneumoniae & $+(4 / 4)$ & ND & $+(4 / 4)$ & $-(0 / 4)$ \\
\hline Klebsiella pneumoniae subsp. ozaenae & $-(0 / 4)$ & $-(0 / 2)$ & $-(0 / 4)$ & $-(0 / 4)$ \\
\hline Klebsiella pneumoniae subsp. rhinoscleromatis & $-(0 / 5)$ & $-(0 / 3)$ & $-(0 / 5)$ & $-(0 / 5)$ \\
\hline Klebsiella terrigena & $-(0 / 5)$ & $+(5 / 5)$ & $+(5 / 5)$ & $-(0 / 3)$ \\
\hline
\end{tabular}


TABLE 1-Continued

\begin{tabular}{|c|c|c|c|c|}
\hline \multirow{3}{*}{ Taxon } & \multicolumn{4}{|c|}{ Oxidation of: } \\
\hline & \multicolumn{2}{|c|}{ Glucose to gluconate $^{a}$} & \multirow{2}{*}{$\begin{array}{l}\text { Gluconate } \\
\text { to } 2-\mathrm{KG}^{b}\end{array}$} & \multirow{2}{*}{$\begin{array}{l}2-\mathrm{KG} \text { to } \\
2,5-\mathrm{KG}^{\mathrm{c}}\end{array}$} \\
\hline & $-P Q Q$ & $+\mathrm{PQQ}$ & & \\
\hline Kluyvera ascorbata & $-(0 / 5)$ & $+(5 / 5)$ & $-(0 / 5)$ & $-(0 / 3)$ \\
\hline Kluyvera cryocrescens & $-(0 / 5)$ & $+(5 / 5)$ & $-(0 / 5)$ & $-(0 / 3)$ \\
\hline Koserella trabulsii & $-(0 / 3)$ & $+(3 / 3)$ & $-(0 / 3)$ & $-(0 / 3)$ \\
\hline Leclercia adecarboxylata & $-(0 / 7)$ & $+(7 / 7)$ & $-(0 / 7)$ & $-(0 / 7)$ \\
\hline Leminorella grimontii & $-(0 / 2)$ & $-(0 / 2)$ & $-(0 / 4)$ & $-(0 / 2)$ \\
\hline Leminorella richardii & $-(0 / 2)$ & $-(0 / 2)$ & $-(0 / 4)$ & $-(0 / 2)$ \\
\hline Leminorella sp. strain $3346-72$ & - & - & - & - \\
\hline Moellerella wisconsensis $2986-78$ & - & - & - & - \\
\hline Morganella morganii & $-(0 / 5)$ & $-(0 / 3)$ & $-(0 / 5)$ & $-(0 / 3)$ \\
\hline Obesumbacterium proteus & $-(0 / 4)$ & $-(0 / 4)$ & $+(4 / 4)$ & $-(0 / 4)$ \\
\hline Pragia fontium & $-(0 / 2)$ & $-(0 / 2)$ & $+(2 / 2)$ & $-(0 / 2)$ \\
\hline Proteus mirabilis & $-(0 / 5)$ & $+(5 / 5)$ & $-(0 / 5)$ & $-(0 / 3)$ \\
\hline Proteus myxofaciens 19692 & - & + & - & - \\
\hline Proteus penneri & $-(0 / 5)$ & $-(0 / 5)$ & $-(0 / 5)$ & $-(0 / 3)$ \\
\hline Proteus vulgaris & $-(0 / 5)$ & $-(0 / 5)$ & $-(0 / 5)$ & $-(0 / 3)$ \\
\hline Providencia alcalifaciens & $-(0 / 5)$ & $-(0 / 3)$ & $-(0 / 5)$ & $-(0 / 3)$ \\
\hline Providencia heimbachae & $-(0 / 4)$ & $-(0 / 3)$ & $-(0 / 4)$ & $-(0 / 2)$ \\
\hline Providencia rettgeri & $-(0 / 5)$ & $-(0 / 3)$ & $-(0 / 5)$ & $-(0 / 3)$ \\
\hline Providencia rustigianii & $-(0 / 5)$ & $-(0 / 3)$ & $-(0 / 5)$ & $-(0 / 5)$ \\
\hline Providencia stuartii & $-(0 / 6)$ & $-(0 / 3)$ & $-(0 / 6)$ & $-(0 / 6)$ \\
\hline Rahnella aquatilis & $+(2 / 2)$ & ND & $+(2 / 2)$ & $+(2 / 2)$ \\
\hline "Salmonella enterica subsp. enterica" & $-(0 / 77)$ & $\mathrm{d}(56 / 77)^{j}$ & $-(0 / 5)$ & $-(0 / 1)$ \\
\hline "Salmonella enterica subsp. salamae" & $-(0 / 3)$ & $+(2 / 2)$ & $-(0 / 3)$ & $-(0 / 1)$ \\
\hline "Salmonella enterica subsp. arizonae" & $-(0 / 3)$ & $+(2 / 2)$ & $-(0 / 3)$ & $-(0 / 1)$ \\
\hline "Salmonella enterica subsp. diarizonae" & $-(0 / 3)$ & $+(2 / 2)$ & $-(0 / 3)$ & $-(0 / 1)$ \\
\hline "Salmonella enterica subsp. houtenae" & $-(0 / 3)$ & $+(2 / 2)$ & $-(0 / 3)$ & $-(0 / 1)$ \\
\hline "Salmonella enterica subsp. bongori" & $-(0 / 3)$ & $+(2 / 2)$ & $-(0 / 3)$ & $-(0 / 1)$ \\
\hline "Salmonella enterica subsp. indica" 1240 & - & + & - & - \\
\hline Serratia entomophila & $+(5 / 5)$ & ND & $+(5 / 5)$ & $-(0 / 2)$ \\
\hline Serratia ficaria & $+(7 / 7)$ & ND & $+(7 / 7)$ & $-(0 / 7)$ \\
\hline Serratia fonticola & $-(0 / 5)$ & $+(5 / 5)$ & $+(5 / 5)$ & $-(0 / 5)$ \\
\hline Serratia grimesii & $-(0 / 7)$ & $+(7 / 7)$ & $+(7 / 7)$ & $+[11 / 11]$ \\
\hline Serratia liquefaciens & $-(0 / 8)$ & $+(8 / 8)$ & $+(8 / 8)$ & $+[8 / 8]$ \\
\hline Serratia marcescens & $+(6 / 6)$ & ND & $+(6 / 6)$ & $+[6 / 6]$ \\
\hline Serratia odorifera & $+(5 / 5)$ & ND & $+(5 / 5)$ & $-(0 / 3)$ \\
\hline Serratia plymuthica & $\mathrm{d}(1 / 4)$ & $+(4 / 4)$ & $+(4 / 4)$ & $-(0 / 4)$ \\
\hline Serratia proteamaculans & $-(0 / 5)$ & $+(5 / 5)$ & $+(5 / 5)$ & $-(0 / 5)$ \\
\hline Serratia rubidaea & $+(4 / 4)$ & ND & $+(4 / 4)$ & $-(0 / 2)$ \\
\hline Tatumella ptyseos & $+(2 / 2)$ & ND & $+(2 / 2)$ & $+(2 / 2)$ \\
\hline Xenorhabdus luminescens & $-(0 / 2)$ & $-(0 / 2)$ & $-(0 / 2)$ & $-(0 / 2)$ \\
\hline Xenorhabdus nematophilus & $-(0 / 2)$ & $-(0 / 2)$ & $-(0 / 2)$ & $-(0 / 2)$ \\
\hline Yersinia aldovae $669-83$ & + & ND & - & - \\
\hline Yersinia enterocolitica & $\mathrm{d}(3 / 5)$ & $d(3 / 5)$ & $-(0 / 5)$ & $-(0 / 3)$ \\
\hline Yersinia frederiksenii & d $(5 / 7)$ & d $(5 / 7)$ & $-(0 / 5)$ & $-(0 / 5)$ \\
\hline Yersinia intermedia 8028 & - & - & - & - \\
\hline Yersinia kristensenii & $+(3 / 3)$ & ND & $-(0 / 3)$ & $-(0 / 3)$ \\
\hline \multicolumn{5}{|l|}{ Yersinia pestis genomic species } \\
\hline Yersinia pestis EV40 & - & - & - & - \\
\hline Yersinia pseudotuberculosis & $-(0 / 6)$ & $-(0 / 3)$ & $-(0 / 6)$ & $-(0 / 2)$ \\
\hline Yersinia ruckeri & $-(0 / 4)$ & $-(0 / 2)$ & $-(0 / 4)$ & $-(0 / 3)$ \\
\hline
\end{tabular}

${ }^{a}$ Tested by acid production from glucose under strongly aerobic conditions and in the presence of iodoacetate (glucose oxidation test). $-\mathrm{PQQ}$, without PQQ; $+\mathrm{PQQ}$, with $10 \mu \mathrm{M}$ PQQ.

${ }^{b}$ Gluconate dehydrogenase test. 2-KG, 2-Ketogluconate.

c 2-Ketogluconate dehydrogenase test. 2,5-KG, 2,5-Diketogluconate.

$d+$, All strains positive; - , all strains negative; $d$, different reactions. When more than one strain was tested, the numbers in parentheses indicate the number of positive strains/number of strains tested. Reactions which were positive at $20^{\circ} \mathrm{C}$ and not at $30^{\circ} \mathrm{C}$ are indicated by brackets. ND, Not done.

${ }^{e}$ Enterobacter agglomerans sensu stricto includes the type strain and DNA relatedness group XIII (6). Groups II to XII are other Enterobacter agglomerans DNA relatedness groups (6).

${ }^{f}$ Enterobacter cloacae groups 1 to 6 are unpublished DNA relatedness groups (unpublished data from Grimont and co-workers). The type strain of the species is in group 1. Groups 4 and 5 corresponded to Enterobacter asburiae.

${ }^{g}$ Prototrophic strains in the Escherichia coli genomic group are commonly referred to as Escherichia coli. Auxotrophic strains which carry an invasivity plasmid are often given a different generic name, Shigella.

${ }^{h}$ Serotypes 6 ( 2 of 4 strains) and 7 ( 4 of 4 strains) were positive. In addition, serotypes 2 through 5, 8, 9, and 12 (one strain each) were negative.

${ }^{i}$ Serotypes $2,4,5,9$, and 11 through 14 (one strain each) were positive. Serotypes $1,3,8,10$, and 18 (one strain each) were negative.

${ }^{j}$ The results for the different serotypes studies were as follows (number of positive strains/number of strains tested): Typhi, 25/33; Paratyphi A, 1/1; Paratyphi B, 20/27; Paratyphi C, 1/1; Cholerae-suis var. Cholerae-suis, 1/1; Cholearae-suis var. Kunzendorf, 1/1; Gallinarum-pullorum, 7/13. 
themi, Erwinia nigrifluens, Erwinia salicis, Moellerella wisconsensis, Proteus penneri, Proteus vulgaris, Yersinia intermedia, Yersinia pestis, Yersinia pseudotuberculosis, and Yersinia ruckeri, Enterobacter agglomerans genomic group VIII, two of the three subspecies of Klebsiella pneumoniae (Klebsiella pneumoniae subsp. ozaenae and Klebsiella pneumoniae subsp. rhinoscleromatis), and some strains of Shigella dysenteriae, Shigella boydii, Salmonella enterica, Yersinia enterocolitica, and Yersinia frederiksenii were negative in all tests of the glucose oxidation pathway. Either these organisms lack this pathway or the corresponding dehydrogenases have requirements for unknown cofactors or conditions not met by our tests. It is our experience that in previous experiments, the glucose dehydrogenase of Klebsiella pneumoniae and the 2-ketogluconate dehydrogenase of Serratia marcescens were not detected because of an insufficient magnesium concentration in the reaction medium and an excessive temperature $\left(30^{\circ} \mathrm{C}\right)$, respectively.

Only five species, Erwinia cypripedii, Ewingella americana, Rahnella aquatilis, Serratia marcescens (at $20^{\circ} \mathrm{C}$ ), and Tatumella ptyseos, produced 2,5-diketogluconate from glucose without a requirement for PQQ. This finding might have some biotechnological interest since 2,5-diketogluconate is a key intermediate in the synthesis of ascorbic acid (24). When PQQ was provided (required for glucose oxidation), Serratia grimesii and Serratia liquefaciens produced 2,5-diketogluconate from glucose. Escherichia blattae, a species rarely isolated or studied, was unique in having gluconate and 2-ketogluconate dehydrogenases without glucose dehydrogenase.

The members of the genera Hafnia, Obesumbacterium, and Pragia were unique in producing only gluconate dehydrogenase.

The diversity of reactions given by representatives of Enterobacter agglomerans genomic groups should help characterize these groups phenotypically. Among the six Enterobacter cloacae genomic groups (unpublished because of a lack of differential tests), genomic group 3 is the only group that is able to oxidize glucose in the absence of added PQQ. Table 1 also provides new characters for differentiating species in the genera Citrobacter, Enterobacter, Erwinia, Klebsiella, Proteus, and Serratia.

In some cases, the study of the glucose oxidation pathway may have epidemiological interest. The single strain of Serratia plymuthica (strain 273) which oxidized glucose in the absence of PQQ belongs to biotype $\mathrm{C} 2 \mathrm{a}$, whereas the other strains tested belong to biotypes $\mathrm{C} 2 \mathrm{~b}$ and $\mathrm{C} 2 \mathrm{c}(10)$. Although different reactions were observed for Salmonella enterica and Shigella spp. in the glucose oxidation test with PQQ, more strains need to be studied before any epidemiological application of this test can be proposed.

The tests used for classification and identification of members of the Enterobacteriaceae (and many other bacteria) do not take advantage of the large diversity of metabolic pathways. The extensive application of DNA hybridization techniques yields genomic species which can hardly be differentiated by conventional phenotypic tests (6). New tests exploring metabolic routes are acutely needed. The diversity of glucose PTS entry routes (4) and glucose oxidation products in the Enterobacteriaceae (a family currently thought to behave like Escherichia coli $\mathrm{K}-12$ ) is encouraging.

\section{ACKNOWLEDGMENT}

This work is dedicated to the memory of Oleg Lysenko.

\section{LITERATURE CITED}

1. Ameyama, M. 1982. Enzymic microdetermination of D-glucose, D-fructose, D-gluconate, 2-keto-D-gluconate, aldehyde and alcohol with membrane-bound dehydrogenases. Methods Enzymol. 89:20-29.

2. Bascomb, S., S. P. Lapage, M. A. Curtis, and W. R. Wilcox. 1973. Identification of bacteria by computer: identification of reference strains. J. Gen. Microbiol. 77:291-315.

3. Bernaerts, M., and J. De Ley. 1971. 2,5-Diketogluconate formation by Chromobacterium. Antonie van Leeuwenhoek J. Microbiol. Serol. 37:185-195.

4. Bouvet, O. M. M., and P. A. D. Grimont. 1987. Diversity of the phosphoenolpyruvate/glucose phosphotransferase system in the Enterobacteriaceae. Ann. Inst. Pasteur (Paris) 138:3-13.

5. Bouvet, O. M. M., and P. A. D. Grimont. 1988. Extracellular oxidation of D-glucose by some members of the Enterobacteriaceae. Ann. Inst. Pasteur (Paris) 139:59-77.

6. Brenner, D. J., G. R. Fanning, J. K. Leete Knudson, A. G. Steigerwalt, and M. I. Kricevsky. 1984. Attempts to classify herbicola group-Enterobacter agglomerans strains by deoxyribonucleic acid hybridization and phenotypic tests. Int. J. Syst. Bacteriol. 34:45-55.

7. Duine, J. A., J. Frank Jzn, and J. A. Jongejan. 1986. PQQ and quinoprotein enzymes in microbial oxidations. FEMS Microbiol. Rev. 32:165-178.

8. Gosselé, F., J. Swings, and J. De Ley. 1980. A rapid, simple, and simultaneous detection of 2-keto-, 5-keto- and 2,5-diketogluconic acids by thin layer chromatography in culture media of acetic acid bacteria. Zentralbl. Bakteriol. Parasitenkd. Infektionskr. Hyg. Abt. 1 Orig. Reihe C 1:178-181.

9. Gottschalk, G. 1979. Bacterial metabolism. Springer-Verlag, New York.

10. Grimont, P. A. D., F. Grimont, H. L. C. Dulong de Rosnay, and P. H. A. Sneath. 1977. Taxonomy of the genus Serratia. J. Gen Microbiol. 98:39-66.

11. Haynes, W. C. 1951. Pseudomonas aeruginosa-its characterization and identification. J. Gen. Microbiol. 5:939-950.

12. Hommes, R. W. J., P. W. Postma, O. M. Neijssel, D. W. Tempest, P. Dokter, and J. A. Duine. 1984. Evidence of a quinoprotein glucose dehydrogenase apoenzyme in several strains of Escherichia coli. FEMS Microbiol. Lett. 24:329333 .

13. Hugh, R., and E. Leifson. 1953. The taxonomic significance of fermentative versus oxidative metabolism of carbohydrates by various gram-negative bacteria. J. Bacteriol. 66:24-26.

14. Katznelson, H., S. W. Tanenbaum, and E. L. Tatum. 1953. Glucose, gluconate and 2-ketogluconate oxidation by Acetobacter melanogenum. J. Biol. Chem. 204:43-59.

15. Lysenko, O. 1961. Pseudomonas-an attempt at a general classification. J. Gen. Microbiol. 25:379-408.

16. Matsushita, K., E. Shinagawa, T. Inoue, O. Adachi, and M. Ameyama. 1986. Immunological evidence for two types of PQQ-dependent $\mathrm{D}$-glucose dehydrogenase in bacterial membranes and the location of the enzyme in Escherichia coli. FEMS Microbiol. Lett. 37:141-144.

17. Meadow, N. D., R. Revuelta, V. N. Chen, R. R. Colwell, and S. Roseman. 1987. Phosphoenolpyruvate:glucose phosphotransferase system in species of Vibrio, a widely distributed marine bacterial genus. J. Bacteriol. 169:4893-4900.

18. Misenheimer, T. J., R. F. Anderson, A. A. Lagoda, and D. D. Tyler. 1965. Production of 2-ketogluconic acid by Serratia marcescens. Appl. Microbiol. 13:393-396.

19. Neijssel, O. M., D. W. Tempest, P. W. Postma, J. A. Duine, and J. Frank Jzn. 1983. Glucose metabolism by $\mathrm{K}^{+}$-limited Klebsiella aerogenes: evidence for the involvement of a quinoprotein glucose dehydrogenase. FEMS Microbiol. Lett. 20:35-39.

20. Postma, P. W., and J. W. Lengeler. 1985. Phosphoenolpyruvate: carbohydrate phosphotransferase system of bacteria. Micro- 
biol. Rev. 49:232-269.

21. Romano, A. H., J. D. Trifone, and M. Brustolon. 1979. Distribution of the phosphoenolpyruvate:glucose phosphotransferase system in fermentative bacteria. J. Bacteriol. 139:93-97.

22. Shinagawa, E., and M. Ameyama. 1982. 2-Keto-D-gluconate dehydrogenase from Gluconobacter melanogenus, membranebound. Methods Enzymol. 89:194-198.
23. Shinagawa, E., K. Matsushita, O. Adachi, and M. Ameyama. 1978. Membrane-bound D-gluconate dehydrogenase of Serratia marcescens: purification and properties. Agric. Biol. Chem. 42: 2355-2361.

24. Sonoyama, T., B. Kageyama, and S. Yagi. 1987. Distribution of microorganisms capable of reducing 2,5-diketo-D-gluconate to 2-keto-L-gulonate. Agric. Biol. Chem. 51:2003-2004. 